\title{
Effect of early and intensive continuous venovenous hemofiltration on patients with cardiogenic shock and acute kidney injury after cardiac surgery
}

\author{
Szu-Yuan Li, MD, ${ }^{\mathrm{a}}$ Wu-Chang Yang, MD, ${ }^{\mathrm{a}}$ and Chiao-Lin Chuang, $\mathrm{MD}^{\mathrm{b}}$
}

Objective: Continuous renal replacement therapy (CRRT) is currently the mainstay renal support for critically ill patients. However, the optimal intensity of CRRT remains debated owing to the heterogeneity of the study populations and CRRT techniques across centers. The present study investigated the beneficial effects of early and intensive continuous venovenous hemofiltration $(\mathrm{CVVH})$ on patients with shock after cardiotomy.

\begin{abstract}
Methods: Patients who had received CRRT for cardiogenic shock and acute kidney injury after cardiac surgery from January 2003 to December 2007 were retrospectively recruited. They were divided into 2 groups according to the delivered dosage of hemofiltration.

Results: The mean duration between intensive care unit admission and initiation of CVVH was $1.4 \pm 0.8$ days. The all-cause mortality by day 30 was $73.3 \%$ and $45.4 \%$ in the low- and high-dose groups, respectively $(P=.002)$. The corresponding in-hospital mortality rate was $82.2 \%$ and $61.8 \%(P=.02)$. No significant difference was seen in the renal recovery of the survivors between the 2 groups.

Conclusions: In patients developing postoperative cardiogenic shock and acute kidney injury after cardiac surgery, an early higher CVVH dose was associated with better in-hospital and long-term survival. Moreover, the beneficial effect of intensive treatment might be more critical in the early perioperative period. (J Thorac Cardiovasc Surg 2014;148:1628-33)
\end{abstract}

Acute kidney injury (AKI) remains a dreaded complication of cardiac surgery, despite substantial advances in surgical techniques, anesthesia management, and cardiopulmonary bypass equipment. The causes of AKI after cardiac surgery have included hypovolemia, systemic inflammation, anemia, hypotension, hypoxemia, and direct ischemia in the case of operations involving vascular interruption. ${ }^{1}$ Depending on the population studied and the criteria used for definition, the frequency of AKI after cardiac surgery has ranged from $0.7 \%$ to $31 \%$, with $5 \%$ to $7 \%$ of patients requiring renal replacement therapy (RRT). ${ }^{2-4}$ Although tremendous innovations in supportive care and RRT have occurred during the past decade, the mortality rate of AKI necessitating RRT has remained extremely high, in excess of $50 \% .^{5,6}$

From the Divisions of Nephrology ${ }^{\mathrm{a}}$ and General Medicine, ${ }^{\mathrm{b}}$ Department of Medicine, Taipei Veterans General Hospital and National Yang-Ming University School of Medicine, Taipei, Taiwan.

This work was supported by the Taipei Veterans General Hospital (grants V102-E2002, V102-B-016 and V95-B1-009) and the National Science Council, Taiwan (grants NSC 101-2314-B-075-038 and NSC 102-2633-B-075-001).

Disclosures: Authors have nothing to disclose with regard to commercial support.

Received for publication Feb 18, 2014; revisions received April 24, 2014; accepted for publication May 2, 2014; available ahead of print June 9, 2014.

Address for reprints: Chiao-Lin Chuang, MD, Division of General Medicine, Department of Medicine, Taipei Veterans General Hospital, No. 201, Sec 2, Shih-Pai Rd, Taipei 11217, Taiwan (E-mail: clchuang@vghtpe.gov.tw).

0022-5223/\$36.00

Copyright $($ C 2014 by The American Association for Thoracic Surgery

http://dx.doi.org/10.1016/j.jtcvs.2014.05.006
As an alternative to traditional intermittent hemodialysis, continuous RRT (CRRT) has now emerged as the leading form of RRT for patients with AKI in the intensive care unit (ICU) worldwide owing to less treatment-related hemodynamic instability, more steady acid-base and electrolyte correction, and subtend fluid removal theoretically. In the past decade, several studies of endotoxemic animals have revealed improved hemodynamics and cytokine removal with high-volume CRRT. ${ }^{7-9}$ In addition, some single-center clinical studies have advocated a RRT dosesurvival relationship, suggesting the beneficial effect of CRRT intensity $>35 \mathrm{~mL} / \mathrm{kg} / \mathrm{h} .{ }^{10,11}$ However, current large, multicenter, randomized controlled clinical trials have failed to support the putative superiority of intensive CRRT for either survival or renal recovery. ${ }^{12-14}$ This discrepancy might have resulted from the clinical heterogeneity of the study populations and practice variations in the application of CRRT across centers. Thus, we conducted a case-control study of patients with shock after cardiotomy, with homogeneity in disease characteristics, timing to the initiation of RRT, and RRT modality. We also analyzed whether intensive CRRT could improve the clinical outcome.

\section{METHODS \\ Study Subjects \\ The present study was a retrospective case-control study approved by the Taipei Veterans General Hospital institutional review board, which waived the need for written informed consent from the participants.}




\section{Abbreviations and Acronyms \\ AKI = acute kidney injury \\ APACHE $=$ Acute Physiology and Chronic \\ Health Evaluation \\ $\mathrm{CVVH}=$ continuous venovenous hemofiltration \\ ECMO = extracorporeal membrane oxygenation \\ EuroSCORE $=$ European System for Cardiac Operative Risk Evaluation \\ IABP $=$ intra-aortic balloon pumping \\ ICU = intensive care unit \\ RRT = renal replacement therapy \\ SOFA $=$ Sequential Organ Failure \\ Assessment}

From January 2003 to December 2007, adult patients who had developed dialysis-requiring AKI after cardiac surgery at Taipei Veterans General Hospital were recruited. Patients who were hemodynamic stable or receiving chronic dialysis for end-stage kidney disease were ineligible for the present study (Figure 1).

\section{Data Collection}

The demographic data were obtained from the medical records. Biochemistry data, such as hemoglobin, albumin, blood urea nitrogen, and creatinine, were routinely obtained before surgery. The baseline estimated glomerular filtration rate was calculated using the Cockcroft-Gault formula as follows: for men, $(140-$ age) $\times$ (body weight $[\mathrm{kg}]) /$ $(0.814 \times$ serum creatinine $[\mu \mathrm{mol} / \mathrm{L}])$; for women, the value was multiplied by $0.85 .{ }^{15}$ The surgery type, cardiopulmonary bypass duration, postoperative requirement for intra-aortic balloon pumping (IABP), and use of extracorporeal membrane oxygenation (ECMO) were obtained from the surgical records. The Acute Physiology and Chronic Health Evaluation (APACHE) II score, Sequential Organ Failure Assessment (SOFA) score, European System for Cardiac Operative Risk Evaluation (EuroSCORE) II, central venous pressure, interval to CRRT initiation, dosage of inotropic agents and continuous venovenous hemofiltration (CVVH), length of ICU stay, and in-hospital mortality were assessed from the medical records. Sepsis was diagnosed in accordance with the American College of Chest Physicians/Society of Critical Care Medicine Consensus Conference guidelines. $^{16}$

\section{CVVH Setting and Dosage}

All patients were admitted to the ICU immediately after surgery. Inotropic support was prescribed when the mean arterial pressure was $<60 \mathrm{~mm} \mathrm{Hg}$. The indications for RRT were as follows: oligouria (urine output $<240 \mathrm{~mL} / 12 \mathrm{~h}$ ) despite fluid resuscitation and intravenous diuretic treatment, hyperkalemia $>6.5 \mathrm{mmol} / \mathrm{L}$, severe acidosis $(\mathrm{pH}<7.2)$, or pulmonary edema. The decision to initiate or terminate RRT and the dosage of $\mathrm{CVVH}$ were determined by the consulting nephrologists. CVVH was accomplished using blood flow rates of 100 to $150 \mathrm{~mL} / \mathrm{min}$ through a double-lumen, $12 \mathrm{~F}$ catheter inserted into a femoral vein. Bicarbonatebased replacement fluid was administered in predilution mode at a dynamically adjusted rate to achieve the desired fluid balance. The amount of effluent was used as a proxy for the treatment dosage. Patients were transitioned from CVVH to intermittent hemodialysis at the judgment of the nephrologists if they became hemodynamically stable. Recovery of renal function was determined from an assessment of urine output and the biochemical data.

During the 6-year enrollment period, 2 types of CVVH machines were used at Taipei Veterans General Hospital. Before 2005, we had only the first-generation, dedicated CRRT machines, which achieved predilutional hemofiltration of about 1000 to $1200 \mathrm{~mL} / \mathrm{h}$. The device included an AK-10 hemodialysis machine (Gambro, Lund, Sweden) for blood pumping and an infusion pump for fluid balance. Since January 2005, the Prisma machines (Gambro Hospal, Kilchberg, Switzerland) were available and routinely prescribed predilutional hemofiltration of $3000 \mathrm{~mL} / \mathrm{h}$. After a 3-month overlap period, all patients with AKI and unstable hemodynamic data received CVVH using the Prisma machines.

\section{Patient Follow-up}

In June 2010, the renal function and vital status of all patients were collected from the medical records of the outpatient clinic or by telephone interview, or both. When a patient had died during the follow-up period, the date of death was established.

\section{Statistical Analysis}

Normally distributed continuous data are presented as the mean \pm standard deviation and analyzed using the Student $t$ test. Numeric data that were not normally distributed are presented as the median and interquartile range and were analyzed using the Mann-Whitney $U$ test. Statistical analysis was performed using the Statistical Package for Social Sciences, version 20.0, software (SPSS, Chicago, Ill). The survival rate of the 2 groups were calculated using the Kaplan-Meier method and compared using the log-rank test. Multivariate stepwise logistic regression analysis was performed to analyze the independent risk factors of in-hospital mortality. Risk factors with $P<.1$ on univariate analysis were entered into the multivariate analysis. All probabilities were 2 tailed.

\section{RESULTS}

\section{Basic Characteristics of Study Population}

A total of 142 patients (mean age, $69.6 \pm 12.1$ years) were included in the present study. All patients required postoperative support with mechanical ventilation and inotropic agent supplementation. The mean SOFA score, APACHE II score, and EuroSCORE II was $16.4 \pm 2.4$, $27.8 \pm 5.2$, and $43.8 \pm 18.9$, respectively. Of the 142 patients, 45 received a lower dose $(18.1 \pm 3.6 \mathrm{~mL} / \mathrm{kg} / \mathrm{h})$ and 97 a higher dose $(45.2 \pm 7.9 \mathrm{~mL} / \mathrm{min} / \mathrm{h})$ of $\mathrm{CVVH}$. The mean interval between ICU admission and initiation of CVVH was $1.4 \pm 0.8$ days. No statistically significant difference was found in the basic characteristics between the 2 groups (Table 1).

\section{Clinical Outcome}

The number of open heart surgery cases and members of the surgical team remained consistent in our hospital during the study period. The mortality rate and CRRT requirement before and after 2005 were comparable (Figure 2). The inhospital mortality rate was $82.2 \%(\mathrm{n}=37)$ in the low-dose group and $61.8 \%(\mathrm{n}=60)$ in the high-dose group $(P=.02)$. The ICU and hospital length of stay were longer in the highdose group (Table 2). Univariate logistic regression analysis identified 9 risk factors for in-hospital mortality, including old age, male gender, emergency operation, lower 


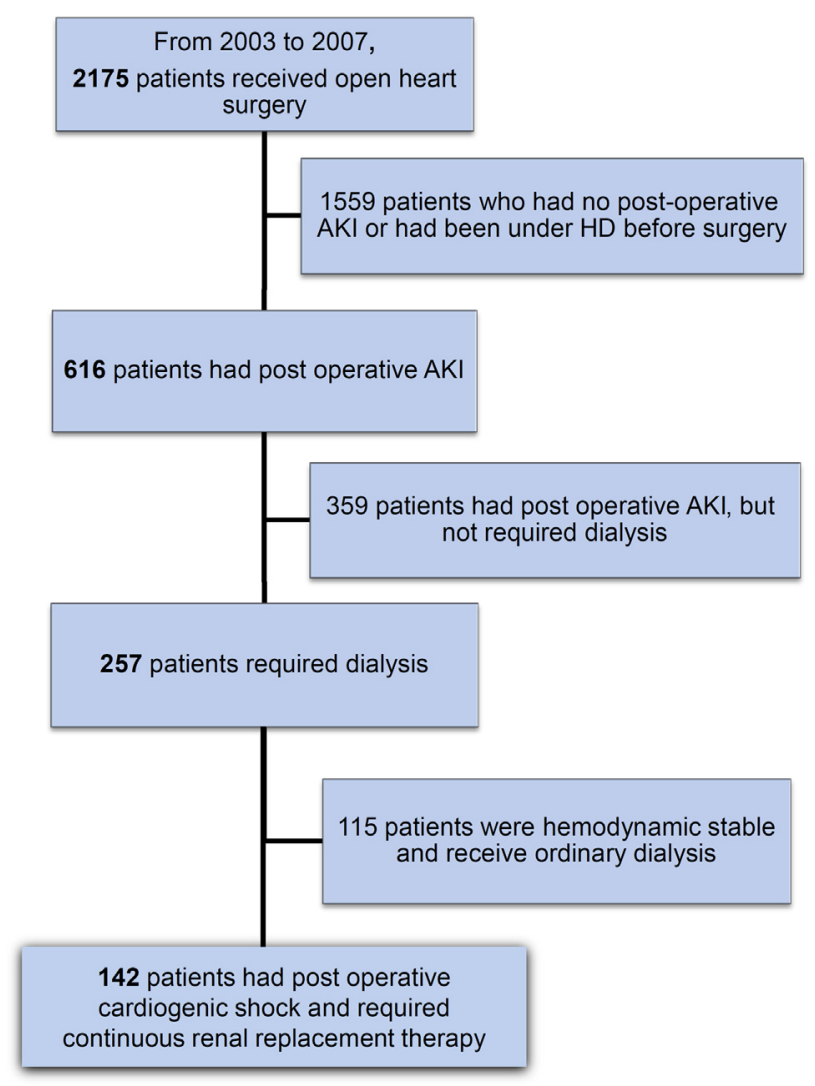

FIGURE 1. Trial profile. $A K I$, Acute kidney injury; $H D$, hemodialysis.

hemoglobin, lower albumin, low-dose CVVH, higher EuroSCORE II, and postoperative requirement for IABP and ECMO (all $P<.05$ ). Thus, these factors were included in a multivariate logistic model, which identified the independent risk factors for in-hospital mortality, including old age, sepsis, low-dose CVVH, higher EuroSCORE II, and postoperative requirement of IABP and ECMO (Table 3). The Kaplan-Meier survival curves are shown in Figure 3.

Overall, 8 patients from the low-dose group and 37 from the high-dose group survived and were discharged from the hospital. Of these 45 patients, $4(50 \%)$ from the low-dose group and $7(19 \%)$ from the high-dose group required long-term hemodialysis after discharge. No statistically significant difference was found in renal recovery between the 2 groups $(P=.172)$.

\section{Evolution of Effect of CVVH Dosage on Survival}

Most mortality events occurred within 1 month after surgery. The beneficial effect of intensive CVVH was greatest perioperatively and declined with time. After multivariate logistic regression adjustment, the odds ratio of low-dose CVVH versus high-dose CVVH at 3 days, 1 week, 2 weeks, 1 month, and 3 months postoperatively was $13.4,7.7,3.8$, 3.3 , and 2.6 , respectively.
TABLE 1. Baseline characteristics

\begin{tabular}{|c|c|c|c|}
\hline Variable & $\begin{array}{c}\text { Low-dose } \\
\text { group }(n=45)\end{array}$ & $\begin{array}{c}\text { High-dose } \\
\text { group }(\mathbf{n}=97)\end{array}$ & $\begin{array}{c}P \\
\text { value }\end{array}$ \\
\hline \multicolumn{4}{|l|}{ Preoperative parameters } \\
\hline Age (y) & $69.1 \pm 14.0$ & $69.9 \pm 11.1$ & .716 \\
\hline Male gender & $75.6(34)$ & $62.9(61)$ & .180 \\
\hline Diabetes & $33.3(15)$ & $47.4(46)$ & .145 \\
\hline Body weight $(\mathrm{kg})$ & $63.3 \pm 11.3$ & $65.6 \pm 13.4$ & .544 \\
\hline $\operatorname{LVEF}(\%)$ & $43 \pm 14$ & $44 \pm 15$ & .304 \\
\hline Hemoglobin (g/L) & $120 \pm 25$ & $113 \pm 19$ & .093 \\
\hline Albumin $(\mathrm{g} / \mathrm{L})$ & $37 \pm 5$ & $37 \pm 5$ & .242 \\
\hline $\mathrm{BUN}(\mathrm{mmol} / \mathrm{L})$ & $12.7 \pm 7.5$ & $11.9 \pm 6.4$ & .536 \\
\hline Creatinine (mmol/L) & $238.7 \pm 176.8$ & $247.5 \pm 221.0$ & .865 \\
\hline $\mathrm{eGFR}\left(\mathrm{mL} / \mathrm{min} / 1.73 \mathrm{~m}^{2}\right)$ & $32.0(15.0-48.5)$ & $30.0(17.4-47.3)$ & .761 \\
\hline \multicolumn{4}{|l|}{ Surgery-related parameters } \\
\hline Urgent operation & $53.3(24)$ & $48.5(47)$ & .212 \\
\hline CABG & $55.6(25)$ & $49.4(48)$ & .589 \\
\hline Valve surgery & $31.1(14)$ & $35.1(34)$ & .706 \\
\hline Aortic aneurysm repair & $20.0(9)$ & $15.4(15)$ & .476 \\
\hline Combined procedures & $17.8(8)$ & $25.7(25)$ & .394 \\
\hline $\mathrm{ACT}(\min )$ & $89(58-130)$ & $93(62-135)$ & .473 \\
\hline CPB time (min) & $160(128-241)$ & $156(117-275)$ & .978 \\
\hline \multicolumn{4}{|l|}{ Postoperative parameters } \\
\hline CVVH dosage $(\mathrm{mL} / \mathrm{kg} / \mathrm{h})$ & $18.1 \pm 3.6$ & $45.2 \pm 7.9$ & $<.001$ \\
\hline CVVH duration (d) & $4(2-8)$ & $12(5-20)$ & .094 \\
\hline $\begin{array}{l}\text { Central venous pressure } \\
\quad(\mathrm{mm} \mathrm{Hg})\end{array}$ & $11.5 \pm 2.4$ & $12.3 \pm 2.2$ & .652 \\
\hline Interval to CVVH (h) & $28.6 \pm 14.2$ & $22.8 \pm 10.2$ & .352 \\
\hline $\mathrm{SBP}(\mathrm{mm} \mathrm{Hg})$ & $81.1 \pm 22.7$ & $81.4 \pm 32.6$ & .563 \\
\hline Dopamine $(\mu \mathrm{g} / \mathrm{kg} / \mathrm{min})$ & $7.3(4.9-10.0)$ & $7.5(4.7-11.8)$ & .676 \\
\hline Epinephrine $(\mu \mathrm{g} / \mathrm{kg} / \mathrm{min})$ & $0.3(0.17-0.40)$ & $0.28(0.12-0.36)$ & .400 \\
\hline IABP & $46.7(21)$ & $41.2(40)$ & .587 \\
\hline ECMO & $35.5(16)$ & $30.9(30)$ & .700 \\
\hline Mechanical ventilation & $100.0(45)$ & $100.0(97)$ & 1.000 \\
\hline $\begin{array}{l}\text { Predialysis eGFR } \\
\quad(\mathrm{mL} / \mathrm{min})\end{array}$ & $15.8 \pm 6.7$ & $17.3 \pm 7.3$ & .452 \\
\hline $\mathrm{FiO}_{2}(\%)$ & $52.1 \pm 20.4$ & $48.9 \pm 20.8$ & .403 \\
\hline SOFA score & $16.7 \pm 2.3$ & $16.3 \pm 2.6$ & .338 \\
\hline APACHE II score & $27.5 \pm 5.8$ & $28.1 \pm 4.7$ & .924 \\
\hline EuroSCORE II & $42.1 \pm 18.2$ & $45.3 \pm 19.4$ & .532 \\
\hline
\end{tabular}

Data presented as mean \pm standard deviation, $\%(\mathrm{n})$, or median (interquartile range). $L V E F$, Left ventricular ejection fraction; $B U N$, blood urea nitrogen; $e G F R$, estimated glomerular filtration rate; $C A B G$, coronary artery bypass grafting; $A C T$, aortic clamp time; $C P B$, cardiopulmonary bypass; $C V V H$, continuous venovenous hemofiltration; $S B P$, systolic blood pressure; $I A B P$, intra-aortic balloon pumping; $E C M O$, extracorporeal membrane oxygenation; $\mathrm{FiO}_{2}$, fraction of inspired oxygen; SOFA, Sequential Organ Failure Assessment; APACHE, Acute Physiology and Chronic Health Evaluation; EuroSCORE, European System for Cardiac Operative Risk Evaluation.

\section{Factors Influencing Survival}

Comparing the background differences between the survivors and nonsurvivors, we found younger age, higher hemoglobin, higher albumin, requirement for IABP or ECMO, higher CVVH dosage, longer length of hospital stay, and lower EuroSCORE II were associated with better patient survival (Table 4). No significant difference was seen for diabetes, urgent surgery, predialysis estimated glomerular filtration rate, APACHE II score, or SOFA score between the survivors and nonsurvivors. 


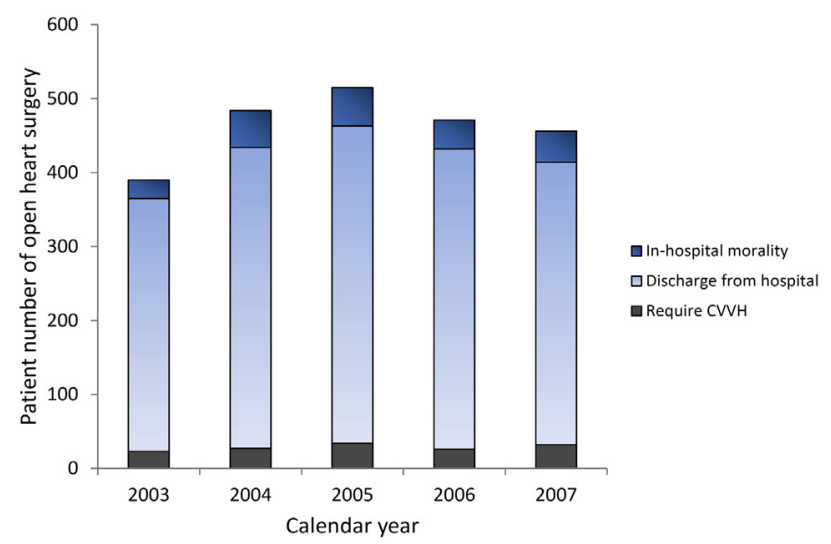

FIGURE 2. Number of cardiac surgery cases in Taipei Veterans General Hospital stratified by year. $\mathrm{CVVH}$, Continuous venovenous hemofiltration.

\section{DISCUSSION}

It has been well accepted that the dialysis dosage affects mortality and morbidity in patients requiring chronic peritoneal and hemodialysis. Thus, the RRT dosage was also thought to play a potential role in the outcomes of patients with AKI. The development and introduction of CRRT represented a critically important change in patient treatment in the ICU. In addition to metabolic control superior to that of other forms of RRT, CRRT allows a better fluid balance, providing a platform for more aggressive nutritional support and possibly having favorable effects on immune function and overall outcome. ${ }^{17}$ Accordingly, CRRT is ideally suited for patients with AKI and significant cardiac disease. In patients undergoing cardiac surgery, AKI has usually been associated with either an inflammatory response or cardiogenic dysfunction. In this clinical context, CRRT might reduce the left ventricular enddiastolic pressure by optimizing the Frank-Starling relationship and improve myocardial performance by removing excessive fluid and circulating myocardial depressants. ${ }^{18,19}$

TABLE 2. Comparison of outcomes between low- and high-dose groups

\begin{tabular}{lccr}
\hline \multicolumn{1}{c}{ Variable } & $\begin{array}{c}\text { Low-dose } \\
\text { group }(\mathbf{n}=\mathbf{4 5})\end{array}$ & $\begin{array}{c}\text { High-dose } \\
\text { group }(\mathbf{n}=\mathbf{9 7})\end{array}$ & $\begin{array}{c}\boldsymbol{P} \\
\text { value }\end{array}$ \\
\hline 1-wk mortality rate & $44.4(20)$ & $17.5(17)$ & $<.001$ \\
30-d mortality rate & $73.3(33)$ & $45.4(44)$ & .002 \\
In-hospital mortality rate & $82.2(37)$ & $61.8(60)$ & .020 \\
ICU length of stay (d) & $8(3-12)$ & $17(8-31)$ & .006 \\
$\quad$ Survivors & $23(10-35)$ & $20(9-33)$ & .716 \\
$\quad$ Nonsurvivors & $5(2-11)$ & $16(6-30)$ & $<.001$ \\
Hospital length of stay (d) & $10(3-23)$ & $29(11-57)$ & $<.001$ \\
$\quad$ Survivors & $46(26-55)$ & $49(30-75)$ & .742 \\
$\quad$ Nonsurvivors & $5(3-11)$ & $19(7-34)$ & $<.001$ \\
Long-term dialysis after & $50(4)$ & $19(7)$ & .172 \\
$\quad$ discharge & & & \\
\hline Data presented as \% (n). ICU, Intensive care unit. & &
\end{tabular}

The Journal of Thoracic and Cardiovascular Surgery $\bullet$ Volume 148, Number 4
TABLE 3. Independent risk factors of in-hospital mortality from multivariate logistic regression analysis

\begin{tabular}{lllc}
\hline \multicolumn{1}{c}{ Variable } & OR & \multicolumn{1}{c}{$\mathbf{9 5} \%$ CI } & $\boldsymbol{P}$ value \\
\hline Age (per 10 y) & 1.64 & $1.15-2.18$ & .014 \\
Sepsis & 4.46 & $1.86-13.21$ & .004 \\
Low-dose CVVH & 2.95 & $1.20-8.31$ & .025 \\
IABP & 2.22 & $0.78-4.82$ & .092 \\
ECMO & 4.12 & $1.36-12.31$ & .013 \\
EuroSCORE II (per 10\%) & 1.18 & $1.03-1.35$ & .03 \\
\hline
\end{tabular}

$O R$, Odds ratio; $C I$, confidence interval; $C V V H$, continuous venovenous hemofiltration; IABP, intra-aortic balloon pumping; $E C M O$, extracorporeal membrane oxygenation; EuroSCORE, European System for Cardiac Operative Risk Evaluation.

However, very few data have been reported regarding the effect of the CVVH dosage for AKI and cardiogenic shock after cardiac surgery. Although recently published randomized studies have failed to detect improvement in mortality with more intensive RRT, the lack of survival benefit does not imply that low- and high-dose CRRT are completely equivalent. ${ }^{12-14}$ In the subgroup analysis, it seemed that the most critically ill patients with hemodynamic instability (cardiovascular SOFA score of 3 or 4) or sepsis might benefit from more intensive therapy. ${ }^{13,14}$ Therefore, our present study recruited critically ill patients with consistent disease characteristics, AKI onset, and RRT modality after cardiac surgery. Our results showed significant outcome improvements with a higher CVVH dose.

In addition to the survival rate, the recovery of renal function and length of ICU stay were postulated as important indicators of clinical outcome. In contrast to previous studies, our results showed a trend toward better renal recovery in patients receiving a higher CVVH dose. The chronic dialysis rate in the survivors from the high- and low-dose group was $19 \%$ and $50 \%$, respectively. However, this difference

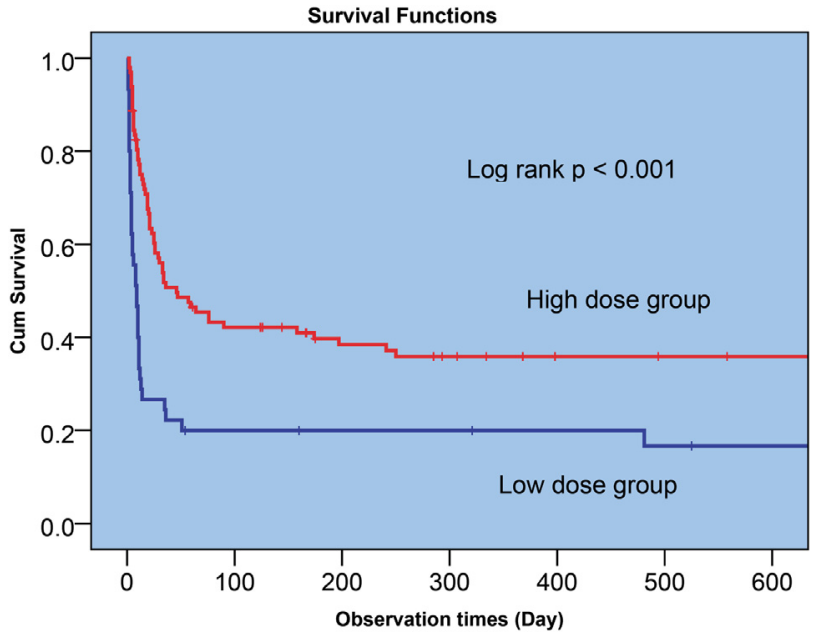

FIGURE 3. Kaplan-Meier analysis of cumulative (Cum) survival curves in 2 groups. 
TABLE 4. Background characteristics of patients with and without inhospital mortality

\begin{tabular}{lccc}
\hline \multicolumn{1}{c}{ Variable } & $\begin{array}{c}\text { Survivor } \\
(\mathbf{n}=\mathbf{4 5})\end{array}$ & $\begin{array}{c}\text { Nonsurvivor } \\
(\mathbf{n}=\mathbf{9 7})\end{array}$ & $\begin{array}{c}\boldsymbol{P} \\
\text { value }\end{array}$ \\
\hline Male gender & $55(25)$ & $72(70)$ & .082 \\
Age (y) & $65.4 \pm 12.6$ & $71.6 \pm 11.4$ & .045 \\
Diabetes & $44(20)$ & $42(41)$ & .081 \\
Urgent surgery & $44(20)$ & $53(51)$ & .077 \\
Hemoglobin (g/L) & $132 \pm 18$ & $108 \pm 26$ & .045 \\
Albumin (g/L) & $39 \pm 6$ & $33 \pm 4$ & .048 \\
IABP & $22(10)$ & $53(51)$ & .008 \\
ECMO & $15(7)$ & $40(39)$ & .002 \\
High-dose CVVH & $82(37)$ & $61(60)$ & .025 \\
Hospital stay (d) & $54.6 \pm 35.9$ & $31.7 \pm 65.9$ & .045 \\
Predialysis eGFR & $14.6 \pm 7.5$ & $17.3 \pm 7.8$ & .652 \\
SOFA score & $16.5 \pm 3.0$ & $16.7 \pm 2.8$ & .402 \\
APACHE II score & $27.9 \pm 5.1$ & $27.9 \pm 4.8$ & .841 \\
EuroSCORE II & $42.7 \pm 12.5$ & $59.8 \pm 13.4$ & .032 \\
\hline
\end{tabular}

Data are presented as $\%$ (n) or mean \pm standard deviation. IABP, Intra-aortic balloon pumping; $E C M O$, extracorporeal membrane oxygenation; $C V V H$, continuous venovenous hemofiltration; $e G F R$, estimated glomerular filtration rate; SOFA, Sequential Organ Failure Assessment; APACHE, Acute Physiology and Chronic Health Evaluation; EuroSCORE, European System for Cardiac Operative Risk Evaluation.

did not reach statistical significance owing to the limited case numbers. Our results demonstrated a longer ICU and hospital length of stay for the high-dose group, despite a similar ICU stay and hospital length of stay between the 2 groups of survivors. Plausibly, this discrepancy could have derived from the very high mortality rate for the patients receiving a low $\mathrm{CVVH}$ dose, especially during the first postoperative week.

The SOFA and APACHE II scores were comparable between the survivors and nonsurvivors (Table 4). This could have been because the basic characteristics of the patients in our study were comparable, including very high score values. Thus, good discrimination between the survivors and nonsurvivors would be dependent on the postoperative parameters, including the requirement for IABP or ECMO. Furthermore, whether organ function improves after better postoperative management, such as a higher CVVH dosage, should be considered. Usually, the trend for the SOFA and APACHE II scores was to progressively decline in survivors. In contrast, the nonsurvivors had a stable and higher score. Accordingly, serial measurement of the SOFA and APACHE II scores might be more useful in predicting the outcome.

Furthermore, consistent with a previous report, ${ }^{20}$ we observed a chronologic change in the beneficial effect of intensive CVVH. The odds ratio for low-dose CVVH reached 13.4 within the first 3 postoperative days and declined gradually thereafter. This pattern implied that the CRRT dosage could make a tremendous contribution to the sudden onset of severe insults or inflammatory storm resulting from a complicated perioperative course but would play a more limited role in refractory illness after support care. This hypothesis was partly supported by the finding that 2 studies with a negative effect of an intensive dose on outcomes had a long period from ICU admission to RRT initiation (average, 6 and 8 days). ${ }^{13,14}$ This duration was significantly longer than the 1.4 days reported by a worldwide practice survey. ${ }^{21}$ It is logical to assume that early intensive RRT might remove more inflammatory mediators from the body pool and decrease the incidence and/ or severity of the downstream inflammatory storm. Some previous studies have shown a survival benefit for early CRRT in severe acute renal failure after cardiac surgery. ${ }^{17,22,23}$ Thus, another key element of intensive CRRT treatment of critically ill patients would be early initiation. This will require multidisciplinary collaboration among cardiac surgeons, intensivists, nephrologists, and allied personnel involved in patient care.

\section{Study Limitations}

The present study had 3 limitations. First, our study was conducted at a single center, which could limit the generalization of its results to other centers. However, the mortality rate and the incidence of dialysis-requiring AKI in our population compared very well with those from previous studies. ${ }^{20}$ Second, men were overrepresented in the present study population because our center is a Veterans hospital. Third, just as is true of other retrospective and observational studies, we were unable to detect and analyze all possible factors that could potentially have affected the clinical outcomes.

\section{CONCLUSIONS}

Our study results indicated that early intensive CVVH was associated with better in-hospital and long-term survival of patients developing postoperative shock and AKI after cardiac surgery. Furthermore, the beneficial effect was more prominent in the acute phase of the complicated perioperative period. Taken together, a "dynamic approach" to the RRT dose, rather than a fixed dose, might be more appropriate for critical care, because critical illness is usually not a static condition. Prospective studies should be conducted to elucidate which mechanisms are associated with the outcome improvement of intensive CRRT.

\section{References}

1. Vermeulen Windsant IC, Hanssen SJ, Buurman WA, Jacobs MJ. Cardiovascular surgery and organ damage: time to reconsider the role of hemolysis. J Thorac Cardiovasc Surg. 2011;142:1-11

2. Ostermann ME, Taube D, Morgan CJ, Evans TW. Acute renal failure following cardiopulmonary bypass: a changing picture. Intensive Care Med. 2000;26: 565-71.

3. Conlon PJ, Stafford-Smith M, White WD, Newman MF, King S, Winn MP, et al. Acute renal failure following cardiac surgery. Nephrol Dial Transplant. 1999;14: 1158-62.

4. Thakar CV, Liangos O, Yared JP, Nelson D, Piedmonte MR, Hariachar S, et al. ARF after open-heart surgery: influence of gender and race. Am J Kidney Dis. 2003;41:742-51. 
5. Zanardo G, Michielon P, Paccagnella A, Rosi P, Calo M, Salandin V, et al. Acute renal failure in the patient undergoing cardiac operation: prevalence, mortality rate, and main risk factors. J Thorac Cardiovasc Surg. 1994;107:1489-95.

6. Cruz DN, Ronco C, Katz N. Neutrophil gelatinase-associated lipocalin: a promising biomarker for detecting cardiac surgery-associated acute kidney injury. $J$ Thorac Cardiovasc Surg. 2012;76:213-20.

7. Bellomo R, Kellum JA, Gandhi CR, Pinsky MR, Ondulik B. The effect of intensive plasma water exchange by hemofiltration on hemodynamics and soluble mediators in canine endotoxemia. Am J Respir Crit Care Med. 2000;161:1429-36.

8. Gomez A, Wang R, Unruh H, Light RB, Bose D, Chau T, et al. Hemofiltration reverses left ventricular dysfunction during sepsis in dogs. Anesthesiology. 1990;73:671-85.

9. Grootendorst AF, van Bommel EF, van der Hoven B, van Leengoed LA, van Osta AL. High volume hemofiltration improves right ventricular function in endotoxin-induced shock in the pig. Intensive Care Med. 1992;18:235-40.

10. Ronco C, Bellomo R, Homel P, Brendolan A, Dan M, Piccinni P, et al. Effects of different doses in continuous veno-venous haemofiltration on outcomes of acute renal failure: a prospective randomised trial. Lancet. 2000;356:26-30.

11. Saudan P, Niederberger M, De Seigneux S, Romand J, Pugin J, Perneger T, et al. Adding a dialysis dose to continuous hemofiltration increases survival in patients with acute renal failure. Kidney Int. 2006;70:1312-7.

12. Tolwani AJ, Campbell RC, Stofan BS, Lai KR, Oster RA, Wille KM. Standard versus high-dose CVVHDF for ICU-related acute renal failure. J Am Soc Nephrol. 2008;19:1233-8.

13. Palevsky PM, Zhang JH, O'Connor TZ, Chertow GM, Crowley ST, Choudhury D, et al. Intensity of renal support in critically ill patients with acute kidney injury. N Engl J Med. 2008;359:7-20.

14. Bellomo R, Cass A, Cole L, Finfer S, Gallagher M, Lo S, et al. Intensity of continuous renal-replacement therapy in critically ill patients. N Engl J Med. 2009;361: 1627-38.
15. Cockcroft DW, Gault MH. Prediction of creatinine clearance from serum creatinine. Nephron. 1976;16:31-41.

16. American College of Chest Physicians/Society of Critical Care Medicine Consensus Conference. Definitions for sepsis and organ failure and guidelines for the use of innovative therapies in sepsis. Crit Care Med. 1992; 20:864-74.

17. Elahi M, Asopa S, Pflueger A, Hakim N, Matata B. Acute kidney injury following cardiac surgery: impact of early versus late haemofiltration on morbidity and mortality. Eur J Cardiothorac Surg. 2009;35:854-63.

18. Caprioli R, Favilla G, Palmarini D, Comite C, Gemignani R, Rindi P, et al. Automatic continuous venovenous hemodiafiltration in cardiosurgical patients ASAIO J. 1993;39:M606-8.

19. Blake P, Hasegawa Y, Khosla MC, Fouad-Tarazi F, Sakura N, Paganini EP. Isolation of "myocardial depressant factor(s)" from the ultrafiltrate of heart failure patients with acute renal failure. ASAIO J. 1996;42: M911-5.

20. Vidal S, Richebe P, Barandon L, Calderon J, Tafer N, Pouquet O, et al. Evaluation of continuous veno-venous hemofiltration for the treatment of cardiogenic shock in conjunction with acute renal failure after cardiac surgery. Eur J Cardiothorac Surg. 2009;36:572-9.

21. Uchino S, Kellum JA, Bellomo R, Doig GS, Morimatsu H, Morgera S, et al Acute renal failure in critically ill patients: a multinational, multicenter study JAMA. 2005;294:813-8.

22. Bent P, Tan HK, Bellomo R, Buckmaster J, Doolan L, Hart G, et al. Early and intensive continuous hemofiltration for severe renal failure after cardiac surgery. Ann Thorac Surg. 2001;71:832-7.

23. Luckraz H, Gravenor MB, George R, Taylor S, Williams A, Ashraf S, et al Long and short-term outcomes in patients requiring continuous renal replacement therapy post cardiopulmonary bypass. Eur J Cardiothorac Surg. 2005;27: 906-9. 